\title{
EL MODELADO ARTIFICIAL DE LA CABEZA DURANTE LA COLONIA. UNA TRADICIÓN MAYA EN EL ESPEJO DE LAS FUENTES HISTÓRICAS
}

\author{
VERA TIESLER \\ Pilar Zabala Aguirre \\ Facultad de Ciencias Antropológicas, \\ Universidad Autónoma de Yucatán
}

Resumen: Este trabajo aporta una mirada alterna sobre la modificación cefálica artificial entre los mayas, concretamente utilizando las observaciones de los cronistas que aún la vieron en la época Colonial. Sin querer, ellas nos comunican motivaciones íntimamente vinculadas con el rol que una vez tuvo la costumbre cefálica dentro de la cosmovisión y la ritualidad cotidiana de los mayas prehispánicos; así, estos testimonios constituyen puntos de partida invaluables para comprender los motivos culturales profundos que el modelado cefálico satisfacía originalmente. Por último, contrastamos y discutimos la información de las fuentes conjuntamente con el registro craneológico en siete series coloniales del territorio cultural maya. Los resultados confirman que el modelado cefálico pronto pierde vigencia en los centros urbanos con mayor presencia europea al mismo tiempo que se observa su pervivencia en los espacios rurales y selváticos más aislados, como los paraderos remotos de la selva lacandona.

Palabras Claves: modificación cefálica artificial, cuerpo humano, Mesoamérica, maya, colonial.

ABSTRACT: This paper contributes an alternative view on artificial head shaping practices among the Maya, which we examine through the lens of those European chroniclers who still witnessed it as a living practice during the colonial era. Unwillingly, these sources testify longstanding cultural motivations for the ancient tradition of modifying infants' vaults, which appear intimately tied to prehispanic Maya worldviews and daily ritual practices. The recognition of these motives provides a valuable point of departure for understanding the deeply embedded cultural roles this head practice once played. The last part of the paper compares and discusses the information provided by the colonial sources jointly with the results obtained from a study of seven colonial skeletal series from the Maya area. Our results confirm that Maya head modeling quickly dwindled within the urban spheres, where the European dominion was most immediate, while surviving over the centuries in the rural hinterlands and the forest refuges, like those of the historical Lacandons.

KeYwords: head shaping, body modifications, Mesoamerica, Maya, colonial.

RECEPCIÓN: 24 de agosto del 2010.

ACEPTACIÓn: 24 de enero del 2011. 



\title{
EL MODELADO ARTIFICIAL DE LA CABEZA DURANTE LA COLONIA. UNA TRADICIÓN MAYA EN EL ESPEJO DE LAS FUENTES HISTÓRICAS*
}

\author{
Vera TIESLER \\ Pilar Zabala Aguirre \\ Facultad de Ciencias Antropológicas, \\ Universidad Autónoma de Yucatán
}

\section{Introducción}

Entre los mayas prehispánicos, la modificación artificial de la cabeza infantil formaba parte de las tradiciones más arraigadas, difundidas y, a la vez, diversificadas de su sofisticado repertorio cultural; esta práctica remite a las esferas íntimas, el "núcleo duro" del armazón ideológico mesoamericano y de sus creencias (López Austin, 2001). Esta costumbre acompañó el desenvolvimiento milenario de los grupos mayas desde sus inicios en el Preclásico Temprano para ir convirtiéndose en siglos posteriores en una práctica bastante generalizada (Tiesler, 1998). Durante los mil quinientos años anteriores a la conquista española, tanto hombres como mujeres mayas, la aristocracia al igual que los sectores populares, lucían portes cefálicos culturalmente producidos (Tiesler, 1999: 327-330; figura 1a, b, c y d).

Contrario a la connotación de "moda" que se le ha dado a la modificación de la cabeza infantil, realmente era una práctica conservadora que trascendía las genealogías al ser practicada por mujeres de segunda o tercera generación en recién nacidos que, después, portaban el resultado visual el resto de su vida (Torres-Rouff,

\footnotetext{
Nuestro sincero reconocimiento a todos aquellos que han contribuido a este trabajo. Estamos agradecidos con las siguientes instituciones y proyectos, cuyos materiales fueron objeto del presente trabajo: Proyectos Arqueológicos Centro INAH Campeche: parque principal de Campeche, atrio del templo de San Francisco, Camp. (arqueólogos Heber Ojeda y Vicente Suárez); Proyectos Arqueológicos Centro INAH Yucatán y Quintana Roo: T’ho, catedral de Mérida (maestro Agustín Peña), Cráneo de Bernadino Cen (arqueóloga Adriana Velázquez) e iglesia de Maxcanú (restaurador Fernando Garcés); Universidad Autónoma de Yucatán: Proyecto Arqueológico Sihó, Yucatán (doctor Rafael Cobos); Dirección de Antropología Física/INAH: Osumacinta, Chiapas, y fotografías tomadas por Vera Tiesler de los restos de Jaina, Palenque, la Angostura y Chichén Itzá (maestro José Antonio Pompa); Museo Na Bolom, San Cristóbal de las Casas, Chiapas: colección Frans Blom (arqueóloga Fabiola Sánchez); Proyecto Arqueológico Lago Mensäbäk, Chiapas (doctor Joel Palka, arqueóloga Fabiola Sánchez). Nuestro trabajo se benefició también de los valiosos comentarios que recibimos de parte de tres dictaminadores anónimos. Además estamos en deuda con el maestro Arturo Romano y la doctora Mercedes de la Garza, quienes hace tiempo apoyaron la búsqueda bibliográfica.
} 


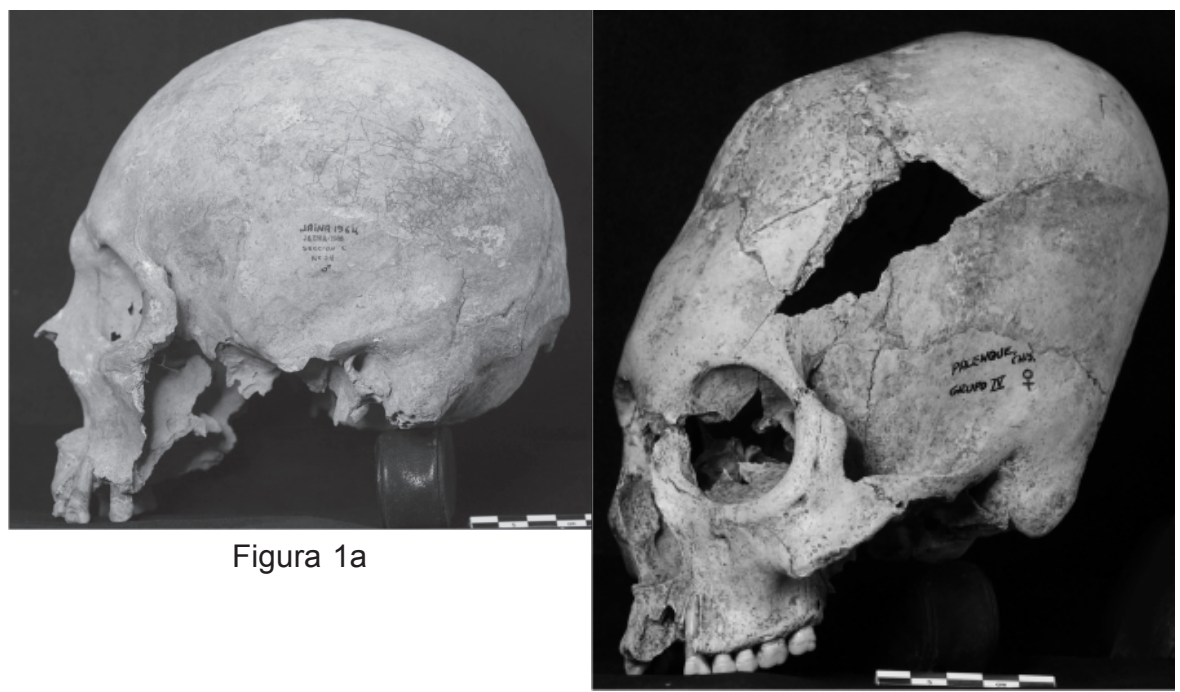

Figura $1 \mathrm{~b}$

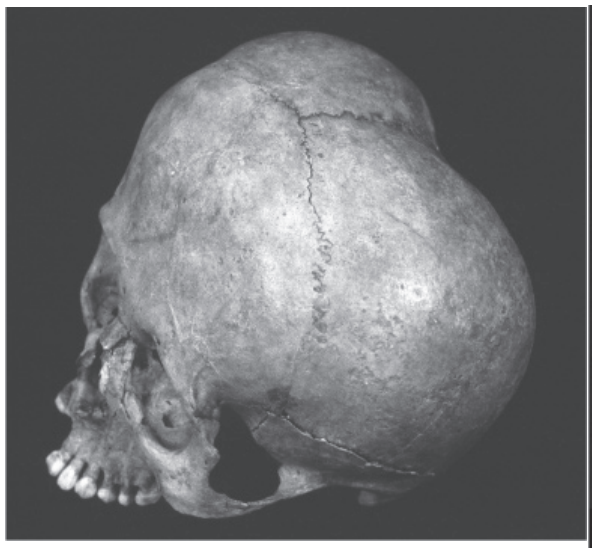

Figura 1c

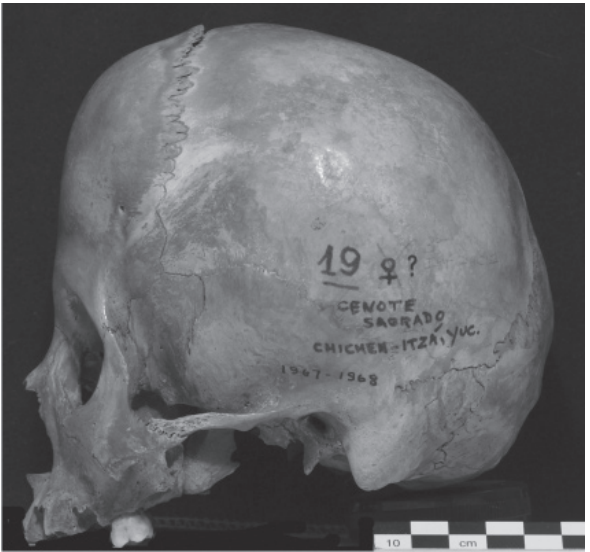

Figura 1d

Figura 1. Diferentes formas cefálicas (todas en norma lateral izquierda, fotos V. Tiesler). a) Cráneo sin modificación artificial (Jaina, Campeche, DAF/INAH); b) cráneo con fuerte modificación tabular oblicua pseudocircular (Palenque, Chiapas, DAF/INAH); c) cráneo con modelado tabular erecto y surco sagital (Argelia, La Angostura, Chiapas, DAF/INAH); d) cráneo con fuerte modelado tabular erecto (Chichén Itzá, Yucatán, DAF/INAH)

2002, 2003; Blom, 2005). Realizada en el seno familiar, la ejecución del modelado cefálico se mantenía en las experimentadas manos de mujeres que practicaban diariamente esta costumbre en sus lactantes. El significado de esta particularidad parece estar relacionado con una visión de vínculo con el cosmos, a la vez que era una expresión de género, de identidad y también de integración social. 
Las formas cefálicas que resultaban de las diferentes prácticas compresoras se caracterizaron por una marcada diversidad hasta el periodo Clásico, pero esto cambiaría pronto. En los siglos posteriores al colapso maya, las prácticas culturales comienzan a homologarse; eso se produce a medida que comienzan a perder aceptación las formas alargadas y reclinadas. Los portes oblicuos se vuelven anacrónicos y son reemplazados gradualmente por configuraciones erectas, las cuales se imprimían en la cabecita del menor al colocarlo dentro de una cuna compresora. Todo parece indicar que los modelados cefálicos erectos -es decir, cabezas artificialmente achatadas, altas y anchas- alcanzaron con los años un estilo uniforme en el área, donde más del 90 por ciento de los cráneos encontrados fueron modificados artificialmente y todos ellos exhiben esta forma (Tiesler, 1998, 1999; tabla 1).

Durante el periodo colonial, con la imposición de las costumbres españolas y la paralela reprobación y supresión de las prácticas autóctonas, cayó primero en desuso y finalmente en abandono la tradición milenaria del modelado cefálico. Su existencia y pervivencia por algún tiempo durante la Colonia la podemos conocer a través de los cronistas, pero después parece ser que la literatura se olvida de ella prácticamente por dos siglos y no es sino hasta el siglo xix cuando surge por primera vez un interés académico por el estudio de esta antigua costumbre en México (y en otros países que comparten el territorio maya). La nueva curiosidad era ahora de índole naturalista y arqueológica y su objeto de atención se dirigió pronto hacia los cráneos deformes de la antiguiedad (véase por ejemplo Stephens y Catherwood, 1963 [1843] y 1969 [1841]). Ya no se atesti-

Tabla 1. Características de las deformaciones craneanas durante el periodo Posclásico Tardío y Colonial (sólo se incluyeron series coloniales representativas).

\begin{tabular}{|l|l|l|}
\hline & $\begin{array}{l}\text { Posclásico mediol } \\
\text { tardío [\%] }\end{array}$ & Colonial \\
\hline $\begin{array}{l}\text { Frecuencia de modificación } \\
\text { artificial (\%) }\end{array}$ & $92.91[\mathrm{~N}=127]$ & $31.12[\mathrm{~N}=77]$ \\
\hline Frecuencia de vendajes anulares & $0[\mathrm{~N}=70]$ & $0[\mathrm{~N}=11]$ \\
\hline $\begin{array}{l}\text { Frecuencia de surco sagital } \\
\text { (variante bilobulada) }\end{array}$ & $34.33[\mathrm{~N}=67]$ & $20[\mathrm{~N}=10]$ \\
\hline $\begin{array}{l}\text { Proporción entre tabulares } \\
\text { oblicuos y erectos }\end{array}$ & $0[\mathrm{~N}=115]$ & $0[\mathrm{~N}=21]$ \\
\hline $\begin{array}{l}\text { Grado promedio de modificación } \\
\text { cuando presente [en una escala } \\
\text { de 0 a 4] }\end{array}$ & $1.9[\mathrm{~N}=118]$ & $1.3[\mathrm{~N}=14]$ \\
\hline
\end{tabular}

•Únicamente se evaluaron cráneos de adultos 
guaba la práctica cefálica en vivo, ya que esta había desaparecido, prácticamente, tiempo atrás.

Durante el siglo xx, el estudio de la modificación cefálica llegó a arraigarse en generaciones de científicos que llegaron a crear "escuelas" para su estudio, como es el caso de la osteología cultural peruana, definida por Pedro Weiss (1962, 1967); la norteamericana, vinculada con la labor de George K. Neuman (1942) y T. Dale Stewart (1974); o la misma mexicana, la cual se anclaba en los trabajos pioneros de Arturo Romano Pacheco $(1965,1974)$ sobre craneotrigonometría mesoamericana. En nuestro país, los trabajos se han centrado mayormente en el registro arqueológico de cráneos y, en menor medida, en los retratos cefálicos.

Además del estudio de los restos arqueológicos, la comunidad académica se ha servido también de las fuentes históricas para subrayar el progresivo abandono de la práctica o ilustrar sus técnicas de elaboración. Aún así no se han desarrollado, hasta la fecha, análisis profundos por parte de los historiadores que hayan evaluado dichas fuentes en su contexto histórico e idiosincrásico. Por tanto, el presente trabajo pretende, basado en los testimonios coloniales sobre la mencionada costumbre, conocer la visión de los cronistas sobre esta práctica que (como otros aspectos de la cosmovisión de las civilizaciones prehispánicas) no supieron interpretar en su justa medida.

\section{Miradas europeas}

Tras la conquista, las modificaciones del cuerpo llamaban poderosamente la atención de los europeos, no sólo aquellas que observaban en el área maya sino también en muchas otras partes del Caribe y de Mesoamérica. Un relato temprano de las costumbres corporales aparece en las Cartas de Relación que Hernán Cortés dirige a los reyes de España, donde atestigua el asombro de los europeos ante las decoraciones del cuerpo que veían entre la población autóctona:

[...] en cada provincia se diferencian [...] los gestos, unos horadándose los orejas y poniéndose en ellas muy grandes y feas cosas, y otras horadándose las ternillas de las narices hasta la boca, y poniéndose en ellas unas ruedas de piedras muy grandes que parecen espejos, y otros se horadaban los bezos de la parte de abajo hasta los dientes, y cuelgan dellos unas grandes ruedas de piedras o de oro, tan pesadas, que les traen los bezos caídos y parecen muy disforme (D’Olwer, 1963: 167).

Contamos también con otro testimonio, el de Juan Molina Solís, específicamente sobre los mayas dentro de su relato sobre la conquista de Yucatán. El autor alude a la importancia que daban a la adecuación de su aspecto físico por consideraciones de índole social y religiosa. Además anota que las modificaciones se efectuaban desde la infancia, recalcando el papel de las madres en el adiestramiento temprano del cuerpo: 
Pero si era una raza bien dotada por la naturaleza, adolecía de vicios de conformación en un gran número de individuos, que acarreaban las necesidades de la crianza, con las preocupaciones más banales sociales y religiosas. A menudo se encontraban sujetos estavados, bizcos, con la cabeza aplastada, horadadas las orejas y arpada la ternilla de las narices. Todos eran defectos artificiales o adquiridos, ora porque las madres, en la edad de la lactancia, llevaban a sus hijos de un lugar a otro ahorcados sobre sus caderas, ya también porque gustaban de usar zarcillos, o bien se imprimían crueles arpaduras para consagrarse con sus divinidades (Molina Solís, 1943: 218).

No obstante, cabe señalar que son escasas las descripciones de los cronistas sobre estas prácticas culturales. Los datos son dispersos y en la mayoría de las ocasiones los relatos hacen referencia al aspecto físico, al ornato o vestido de los indígenas y entonces simplemente se describe, por lo general, la forma de las cabezas. En algunas ocasiones, consideran que tal modificación se realizaba para que pudieran soportar una mayor carga en las cabezas y poder transportar mejor cualquier bulto, como se puede observar en el siguiente párrafo:

Creen que es cosa bella tener las frentes pequeñas y cubiertas con los cabellos y sin ninguna nuca, la cual, para que puedan llevar carga, se la aplanan por las parteras en cuanto ven la primera luz, porque entonces la calavera es muy tierna y esa figura se conserva por los recién nacidos acostados en sus cunas (Hernández, 2001: 111).

Sin embargo, también existen autores que van más allá de la simple descripción de los rasgos físicos o del atavío de los indígenas y que tratan de ofrecer una explicación más exhaustiva sobre esta costumbre, como se verá más adelante. Fray Diego de Landa y fray Bartolomé de las Casas relacionan la práctica con aspectos de salud y enfermedad o de identidad grupal. De la misma forma, también consideraban las modificaciones corporales como indicios de jerarquía social o de valentía; cuanto más modificaciones realizadas en sus cuerpos más audaces aparecían a los ojos de sus compañeros, a la vez que infundían un mayor temor a los enemigos.

Siguiendo el vínculo con la jerarquía y la identidad, en este caso de índole militar, Cristóbal del Castillo manifiesta en su crónica, en una breve frase, la misma reflexión para el caso de los mexicanos. Escrito en náhuatl y traducido al castellano se puede leer: "los guerreros, los varones, los tehihuaque ("los que tienen cargo"), los quahiqueque ("raspados de la cabeza") que se consideran altos grados en la jerarquía militar" (Castillo, 2001: 99).

Está claro que los cronistas cuentan lo que ven. En este sentido no puede argumentarse nada en contra; la situación sólo varía a la hora de efectuar una interpretación ritual o religiosa. En ello intervenía un pensamiento y una ideología muy alejados de la visión de los nativos con quienes se encontraron los europeos y toda explicación cercana a las concepciones espirituales de los indígenas no la entendían ni, en la mayoría de los casos, pretendían interpretarla, debido a que los europeos estaban imbuidos de una educación y unas creencias espirituales 
completamente diferentes. Para tratar de comprender la religión prehispánica adoptaban conceptos de su propia tradición con el fin de entender o explicar su significado, como cuando asociaban los antiguos ídolos con la figura del demonio de la cultura occidental (Zabala, 2009: 6). Si tenemos en cuenta este último hecho, todo aquello que tuviera la más mínima traza de interpretarse desde el punto de vista religioso era considerado ya de una forma peyorativa y, por tanto, había de ser exterminado rápidamente. De tal forma que la mayoría de estos autores no podía aceptar las creencias indígenas, a las que consideraban idolátricas y prácticas aberrantes; por ello, sus interpretaciones solían ser condenatorias.

También debemos considerar que en el universo de la religión católica Dios hizo al hombre a su imagen y semejanza; por tanto, se consideraría un gran sacrilegio el deformar tal imagen. Esta idea se observa perfectamente en Pedro Cieza de León cuando se refiere a la modificación cefálica entre los andinos: "Los cangues y otros comarcanos [...] y estos muchos lo hacen y no contentándose con las cabezas que Dios les da quieren ellos darles el talle que más les agrada" (Cieza de León, 1984: 227).

En este sentido, la modificación de la fisonomía que "Dios les ha dado" se considera como sacrilegio, ya que anteponen algo tan superficial como su ornato al "favor" que el Dios católico había hecho a los hombres al crearlos a su propia imagen y semejanza.

Especialmente este último aspecto nos obliga a mantener cautela a la hora de la interpretación cultural. Algunas fuentes hispanas, incluso, resaltan lo perjudicial o "primitivo" de la plástica cefálica; otras llegan a condenarla categóricamente como acto de idolatría. En el mundo andino del Perú, por ejemplo, donde los modelados cefálicos habían adquirido un papel similar al que tenían en Mesoamérica, el arzobispo fray Gerónimo de Loayza prescribió en el Sínodo de Lima "que la superstición de amoldar las cabezas de los muchachos de ciertas formas [...] del todo se quiten” (apud Pardal, 1938: 69).

\section{Los significados culturales en el espejo de las fuentes}

Más allá de la actitud europea sobre las prácticas corporales mesoamericanas o mayas, nos interesaba examinar de cerca lo que las fuentes españolas pueden dejar entrever sobre los significados culturales autóctonos y la costumbre de las modificaciones craneanas. Naturalmente hay que emprender esta tarea con mucha cautela, ya que la mayoría de las fuentes españolas están dotadas de nociones etnocentristas y de una actitud occidental reprobatoria, tal y como asentamos líneas arriba.

Entre las afirmaciones europeas resalta la importancia que muchos escritos otorgan al modelado de la cabeza como medida para reducir el occipucio o "colodrillo", que según el Diccionario de autoridades significa la parte posterior de la 
cabeza (RAE, 1990: 419) el cual entre los antiguos mexicanos se creía un locus vulnerable, dotado de energía potencialmente perniciosa o negativa (López Austin, 1989: 209-212; véase también Tiesler y Cucina, 2010). Parece que la parte trasera de la cabeza era consideraba como una de las zonas que podían desequilibrar la comunicación entre centros anímicos del cuerpo humano y afectar o poner en riesgo el bienestar e incluso la vida de las personas: peligro contra el cual había que protegerse eliminando la energía perniciosa que emanaba desde el occipucio. Este proceso de reducción de la parte trasera de la cabeza se detalla en una referencia de Francisco del Paso y Troncoso sobre las costumbres de los mexicanos coloniales:

Se caracterizan por su modesta presencia física, por el color pardo, por los grandes ojos, por la frente amplia, por la nariz, por la nuca plana aunque esta se debe a la acción de los padres [...] (ellos) consideran de hecho que sea un indicador de belleza las frentes pequeñas y ricas de cabellos y la nuca prácticamente inexistente que viene comprimida por el obstetra (las parteras) por medio de la aplicación de un peso desde cuando ven la luz, cuando el cráneo es tierno y mantiene esa forma cuando el niño viene depositado supino en la cuna [...] (Paso y Troncoso, 1926; cap. 25; las cursivas son nuestras).

Aunque de forma menos detallada, también los testigos oculares de los mayas yucatecos del siglo xvi otorgan un papel importante al occipucio en el proceso de la modificación cefálica. Landa, por ejemplo, menciona que se apretaba el colodrillo hasta que la cabeza quedaba chata:

[...] a los cuatro o cinco días de nacida la criaturita poníanla tendidita en un lecho pequeño, hecho de varillas, y allí, boca abajo, le ponían entre dos tablillas la cabeza: la una en el colodrillo y la otra en la frente entre las cuales se la apretaban tan reciamente y la tenían allí padeciendo hasta que acabados algunos días les quedaba la cabeza llana y enmoldada, como la usaban todos ellos (Landa, 1982: 54).

Más explícita es la información de las fuentes sobre los indígenas náhuatlizados de Guatemala del siglo xvı al afirmar Francisco López de Gómara en su Historia de la conquista de México: "Las parteras hacen que las criaturas no tengan colodrillo, y las madres las tienen echadas en cunas de tal suerte que no les crezca porque se precian sin él” (López de Gómara, 1987: 246). Esta afirmación no sólo advierte sobre el motivo para evitar el crecimiento cefálico hacia atrás por medio de la compresión en cuna, sino también alude a una segunda práctica relacionada que comparte la finalidad de eliminar el occipucio; en este caso, eran las parteras las que efectuaban la técnica.

Tomando en cuenta que los raspados, hundimientos e incluso aperturas en vida del occipucio infantil (denominados "lesiones supra-inianas" en la literatura antropológica) se observan también en cráneos mayas (Tiesler, 2006), nos preguntamos si Landa se refería a una operación no con fines terapéuticos prácticos 
sino más bien culturales cuando recalca que "era tanta la molestia y el peligro de los pobres niños, que algunos peligraban”. El autor fue testigo de cómo agujereaban la cabeza a un infante por detrás de las orejas y consideraba que "así debían hacer a muchos” (Landa, 1982: 54). Quizá tampoco sea una coincidencia que el occipucio fuera la única parte donde los mayas yucatecos del siglo xvI se dejaban crecer el cabello (Barrera Vázquez, 1938: 91). Bien podía ser que, al cubrir el colodrillo, el pelo cumpliera una función protectora.

Aparte de las frecuentes referencias anatómicas y, en concreto, al occipucio, llama la atención que las descripciones coloniales aparenten otorgar poca o nula importancia al resultado final del modelado infantil. Esta observación es extensiva a las descripciones coloniales sobre Mesoamérica, cuya ausencia sorprende a primera vista ante la elocuencia de los relatos culturalistas que versan sobre las sociedades del Altiplano y ante la popularidad que la costumbre cefálica gozaba en muchas áreas, como lo evidencian las colecciones craneanas del periodo Posclásico Tardío y del contacto (Dávalos, 1951; Romano, 1974).

Quizá la falta de interés en el aspecto visual puede explicarse por la uniformidad de los artificios cefálicos logrados en Mesoamérica durante los siglos inmediatamente anteriores al contacto europeo, tal como evidencia el registro craneológico para esta época (sobre el área maya, cf. tabla 2). Entonces había un franco predominio de semblantes achatados y anchos, todos logrados con la cuna deformatoria (tabulares erectos; Tiesler, 1998). Por tanto, quizás los observadores no lo consideraran tanto como una modificación artificial sino como una característica física propia de las poblaciones nativas de estas regiones. Esta uniformidad de look contrasta notablemente con la variedad impresionante de artificios cefálicos andinos predominante durante la misma época (Weiss, 1962). Para esta esfera cultural, los relatos costumbristas otorgaban importancia a cada forma cefálica particular como un emblema visible de estatus, distinción y pertenencia étnica. Concretamente, fray Bartolomé de las Casas señaló al respecto:

A aquesta diligencia destas señales para cognocerse las personas de qué provincias eran, parece poderse ayuntar la costumbre antigua, que también tiene cada provincia, de formar las mismas cabezas, porque fuesen cognoscidos los vecinos de cada una dellas. Y así, cuando infantes les acababan de nascer y de allí adelante, mientras tenían las cabezas muy tiernas, les ataban ciertas vendas o paños con que se las amoldaban según la forma que querían que tuviesen las cabezas; y así, unos las formaban anchas de frente y angostas del colodrillo; otros, altas y empinadas, y otros bajas; otros, angostas; otros altas y angostas; otros, altas y anchas, y otros de otras maneras; finalmente, que en la forma de las cabezas tenían muchas invenciones, y ninguna provincia, al menos de las principales, había que tuviese forma diferente de las otras, de cabezas (Las Casas, 1967: 594).

Estas especificaciones detalladas contrastan con las referidas al mundo mesoamericano del siglo xvı. Fray Bernadino de Sahagún sólo hace mención de la modificación artificial del cráneo, tal y como se practicaba en Veracruz, al afirmar 
parcamente que los totonacos "tienen cara larga y las cabezas chatas y que en sus tierras hacen grandísimos calores” (1989: 606). Fray Francisco de Bobadilla, al referirse a las costumbres y creencias locales de los indígenas nahuatlizados de Nicaragua, recalca la noción de "hermosura", añadiendo otros posibles motivos prácticos que conllevaba la costumbre, como promover un carácter dócil y el endurecimiento de la cabeza para soportar un mayor peso:

F. ¿Cómo no tenéis vosotros la cabeza de la hechura que los cristianos?

$Y$. Cuando los niños nacen, tienen las cabezas tiernas y hacénselas como veis que las tenemos con dos tolondrones a los lados dividiendo y queda por medio de la cabeza un gran hoyo de parte a parte; porque nuestros dioses dijeron a nuestros pasados que así quedamos hermosos y gentiles hombres, y las cabezas quedan más recias para las cargas que se llevan en ellas (fray Francisco de Bobadilla, citado por D’Olwer, 1963: 352).

Por último, los testimonios de los cronistas coloniales también hablan sobre la dimensión costumbrista de la plástica cefálica y así nos brindan puntos de partida fundamentales para valorar y revalorizar motivos rituales, aparatos y técnicas deformadoras y riesgos de salud concomitantes al proceso de compresión cefálica.

En su relato sobre los mayas yucatecos coloniales, Landa especifica las técnicas y los riesgos inherentes de la práctica deformatoria. Al lado, introduce otra dimensión ritual asociada con la modificación cultural. Esta corresponde a las festividades que seguían a su término: el hetz ek $^{*}$ o la imposición del nombre que el niño iba a llevar por parte del sacerdote indígena, quien además predecía el destino del niño, tal como Landa afirma en su obra Relación de las cosas de Yucatán: "y cuando ya les habían quitado el tormento de allanarles las frentes y cabezas iban con ellos al sacerdote para que les viese el hado y dijese el oficio que había que tener y pusiese el nombre que había de llevar el tiempo de su niñez" (Landa, 1982: 58).

Tal y como señala Landa en páginas anteriores de su obra, la compresión de la cabecita infantil era una operación cotidiana que duraba meses e incluso años, quedando así enmarcada entre las ceremonias que se efectuaban luego del nacimiento y aquellas otras que se realizaban mucho tiempo después. Según esto y los argumentos arriba asentados sobre su papel organoplástico, la práctica cefálica debía preparar al pequeño o a la pequeña para las ceremonias de primera infancia que le seguían, fuese la primera colocación sobre la cadera o hetz mek, mencionadas por el fraile, la elección del oficio que debía desempeñar en su vida adulta o la asignación del nombre y del tonal (Bonavides, 1992: 408-411).

Parece ser que estas festividades mayas tenían en común consagrar la identidad y el lugar que debería tener el nuevo miembro de la familia dentro de la comunidad y el cosmos. Pensamos por tanto que las maniobras sobre la cabeza infantil, el acto repetido de envolverla, cubrirla, masajearla y apretarla, tuvieron

N. del E. Se está respetando la ortografía de las autoras. 
que haber constituido medidas combinadas de fortalecimiento activo para el desenvolvimiento (promover el calor anímico, la fijación de las esencias anímicas) y de prevención contra daños como la pérdida de energía vital del tonal.

Aunque sean escuetos y etnocéntricos, los testimonios coloniales sobre la zona maya, y sobre Mesoamérica en general, sí dan valiosos indicios sobre el papel cultural de la modificación craneana en los tiempos del contacto. Las fuentes hacen hincapié en las incomodidades sufridas por los afectados, apuntando así hacia la importancia cultural que debía haber tenido esta costumbre en el proceso de la crianza infantil.

\section{El destino de la costumbre tras la Conquista}

Tras nuestra incursión en el mundo colonial, queda implícito que la sociedad maya de principios del siglo xVI $-\mathrm{y}$ probablemente la mesoamericana en general- empleaba el modelado de la cabeza infantil para fines diversos, motivos todos que seguramente estaban impregnados de una profunda importancia cultural, concatenados con otros numerosos aspectos de la realidad vivida dentro del seno familiar, en la comunidad y en la sociedad en general. Este panorama prehispánico contrasta con el declive que la costumbre cefálica experimentó tras el contacto europeo, aspecto que invita a una serie de reflexiones y preguntas: ¿en cuánto tiempo fue abolido del repertorio indígena esta tradición familiar? ¿Cuáles fueron las circunstancias y motivos implicados en su declive?

Si bien los mismos cronistas dan información que permite interpretar el abandono de esta costumbre como una reacción a la actitud reprobatoria europea, conviene complementar la información histórica con testimonios más objetivos, como los obtenidos de los registros craneanos recuperados del área maya. Para los fines de este trabajo hemos examinado la presencia y la extensión del modelado cefálico en seis series esqueléticas, cuya evaluación deriva de un estudio todavía en proceso (Tiesler, 1998, 1999, s.a.; véase también Fernández et al., 2010; Tiesler, Zavala y Peña, 2003; Tiesler y Oliva, 2010; tabla 2). La colección más amplia procede de un camposanto multiétnico de la colonia temprana, ubicada en el subsuelo del parque Central de Campeche. Cerca de este lugar fue recuperada también otra población colonial, presumiblemente indígena, en el atrio del ex convento de San Francisco en Campeche. Una serie esquelética urbana que se supone igualmente de época colonial es la procedente del atrio de la catedral de Mérida, Yucatán. En otra zona, relativamente periférica como es la iglesia colonial de Osumacinta, en Chiapas, fue recuperada una serie con cuatro cráneos evaluables, probablemente de identidad mestiza. Todavía de un ámbito más rural (y, por lo tanto, más alejados de los centros de poder europeo) son los restos de una urna infantil colonial, emplazada en una estructura del sitio prehispánico de Sihó, Yucatán, que en aquel momento ya debía estar en ruinas. Incluimos también el cráneo asignado al legendario general rebelde Bernadino 


\begin{tabular}{|c|c|c|c|}
\hline $\begin{array}{l}\text { Sitio y marco } \\
\text { cronológico probable }\end{array}$ & $\begin{array}{c}\text { Tipo } \\
\text { de contexto }\end{array}$ & $\begin{array}{l}\text { Número de cráneos } \\
\text { con modificación } \\
\text { artificial [N] }\end{array}$ & Tipo de modificación \\
\hline $\begin{array}{l}\text { Plaza Central de } \\
\text { Campeche, Campeche } \\
\text { (siglos xvI y xvII) }\end{array}$ & Urbano & $4[\mathrm{~N}=6]$ & $\begin{array}{l}\text { Únicamente tabular } \\
\text { erecto }\end{array}$ \\
\hline $\begin{array}{c}\text { Atrio del ex convento } \\
\text { San Francisco, Campeche, } \\
\text { Campeche (siglos xvı y xvII) }\end{array}$ & Urbano & $7[\mathrm{~N}=45]$ & $\begin{array}{l}\text { Únicamente tabular } \\
\text { erecto }\end{array}$ \\
\hline $\begin{array}{l}\text { Atrio de la catedral } \\
\text { de Mérida, Yucatán } \\
\text { (Siglos xVI y xVII) }\end{array}$ & Urbano & $0[\mathrm{~N}=6]$ & Sin modificación \\
\hline $\begin{array}{l}\text { Cráneo de Bernardino } \\
\text { Cen, Yucatán }\end{array}$ & Rural & $0[\mathrm{~N}=1]$ & Sin modificación \\
\hline $\begin{array}{l}\text { Iglesia de Maxcanú, } \\
\text { Yucatán }\end{array}$ & Rural & $0[\mathrm{~N}=1]$ & Sin modificación \\
\hline $\begin{array}{l}\text { Sihó, Yucatán } \\
\text { (siglos xVI a xVIII) }\end{array}$ & Rural & $1[\mathrm{~N}=1]$ & $\begin{array}{l}\text { Únicamente tabular } \\
\text { erecto }\end{array}$ \\
\hline $\begin{array}{c}\text { Osumacinta } \\
\text { (siglos xVI y xVII) }\end{array}$ & Rural & $0[\mathrm{~N}=3]$ & Sin modificación \\
\hline $\begin{array}{c}\text { Santuario de cueva, } \\
\text { Mensabak, Sierra Lacandona, } \\
\text { Chiapas (¿siglos xVI a xIx?) }\end{array}$ & Rural & $21[\mathrm{~N}=21]$ & $\begin{array}{l}\text { Únicamente tabular } \\
\text { erecto }\end{array}$ \\
\hline
\end{tabular}

Tabla 2. Presencia de las deformaciones craneanas durante el periodo colonial en las series esqueléticas coloniales evaluadas (en relación con el número de casos evaluables $[\mathrm{N}]$ )

Cen de la Guerra de Castas, quien murió a manos de las tropas gubernamentales en Xulub, Yucatán, en 1875 (Tiesler, 2001). Su calota ya no evidencia trazas de la costumbre maya. Más recientes parecen ser otros restos humanos, que se presuponen coloniales pero también poscoloniales, venerados como ancestros por los lacandones del norte en la Sierra Chiapaneca. Pues bien, todos los cráneos que registramos en estos santuarios escondidos en medio de la selva mostraban modificación artificial (Tiesler et al., 2010).

Aún así, las cifras que obtuvimos de los resultados globales de los estudios de poblaciones que vivían antes y después del contacto (Tiesler, s.a.), subrayan el declive dramático de la costumbre (tabla 1). Si en vísperas de la Conquista prácticamente todos los mayas lucían todavía portes artificiales de la cabeza al igual que en muchos otros territorios culturales de la gran Mesoamérica Posclásica, después tan sólo una tercera parte de los cráneos presumiblemente indígenas de nuestras muestras exhiben modificación cultural. Incluso aquellos individuos que aún muestran compresión cefálica presentan modificaciones menos pronunciadas que en tiempos prehispánicos; únicamente ostestan la modalidad tabular erecta intermedia, a veces con uso de banda sagital. 
En el caso específico de Campeche podemos asumir por los resultados obtenidos que allí el modelado seguía practicándose entre los mayas, aunque de forma reducida, durante el tiempo de funcionamiento del camposanto, es decir, durante la segunda mitad del siglo xvı y posiblemente en parte del xvII. En el grupo identificado como indígena/mestizo, son únicamente tres de once individuos (27.3\%) los que muestran vestigios de modelado cefálico (Tiesler y Oliva, 2010). Muy superior es la proporción de los indígenas sepultados debajo del atrio del convento de San Francisco, en las afueras de la villa europea, con cuatro de seis cráneos evaluables (66.7\%) exhibiéndola (tabla 2). Interesa saber que, a diferencia de las series campechanas, ninguno de los cráneos del asentamiento colonial de Osumacinta, en Chiapas, o de la veintena de osamentas rescatadas debajo del atrio colonial de la catedral de Mérida evidenciaban señales de la práctica pese a la ascendencia indígena que mostraba la gran mayoría de los esqueletos estudiados (Beristáin, 1996; Tiesler, 1998; Tiesler et al., 2003; tabla 2).

Nos preguntamos, ¿qué impacto habrían tenido y qué respuesta causaron las vistosas señas de identidad autóctonas en un panorama social dominado por españoles? ¿Qué transformaciones sufrieron durante el proceso de hispanización que se produjo en Campeche al igual que en las otras ciudades peninsulares recién conformadas? ¿Acaso ocurrieron de la misma forma en las comunidades rurales o en los reductos selváticos? Pensamos que la clave para evaluar el impacto colonial de estas y otras prácticas bioculturales mayas está en que eran perfectamente visibles, lo que las distinguía de otras tradiciones menos evidentes y, por lo tanto, menos sujetas a las presiones ejercidas por parte de los nuevos sectores dominantes (mismos que pretendían la total asimilación y uniformidad cultural de los sectores autóctonos). La convivencia maya y española en el siglo xvi en las afueras de la villa de Campeche y pronto también dentro de los barrios, destinados a la población “india”, necesariamente implicaba un control e imposición directa muy superior mediante la prohibición, el castigo o al menos la reprobación de sus referentes culturales de antaño, tanto por parte de las instituciones civiles como de las eclesiásticas.

Por tanto, el impacto visual que causaban los artificios cefálicos o las decoraciones dentales expuestos al público, antes señas de pertenencia e inclusión cultural, pronto debió haber generado una transformación radical en las personas que los portaban por denotar exclusión y extrañeza en el nuevo tejido multirracial y cultural de la colonia española. Otros aspectos que seguramente tuvieron un papel en el abandono de estas prácticas pueden encontrarse en el mismo mestizaje. Para los mayas, como para todas las culturas nativas americanas, el proceso de la conquista y posterior colonización estaba enmarcado por la catástrofe, no sólo demográfica sino cultural y espiritual; y el sentido de quiebra y de fracaso que afectaba su autoestima y autodefinición, al tiempo que las presiones ibéricas, persuadían su aculturación y la asimilación del nuevo orden (Chuchiak IV, 2006: 10-15). 
El declive de la práctica observada en los restos de la plaza de Campeche y la falta de evidencias en las muestras del atrio de la catedral de Mérida y el camposanto de Osumacinta podrían ser una señal de que en el ámbito urbano se perdió antes la costumbre. Ello puede deberse a diversas circunstancias: en primer lugar, la rápida aculturación que provenía de la cercanía y/o convivencia con pobladores de ascendencia española, lo que tendría como consecuencia la pérdida de tales prácticas. En segundo lugar, hay que tener en cuenta que la emigración de los indígenas de sus lugares de origen para ir a servir a los españoles o trabajar en la ciudad tendría como consecuencia que la pérdida de sus costumbres ancestrales fuera más rápida, además de la mayor celeridad en la adopción y asimilación de las prácticas culturales de la población colonizadora. Y, por último, y no menos importante, el control religioso o civil (por parte de la Iglesia y demás instituciones) había de ser mucho más efectivo en los ámbitos urbanos; esto impediría la pervivencia de la costumbre, más fácil de realizar en poblaciones apartadas y dispersas donde la inexistencia de población europea o el más difuso control religioso permitiría la continuidad de dichas prácticas.

En este sentido, interesa manifestar que los resultados derivados de contextos urbanos (aunque de reducido potencial generalizador debido a un número de muestras insuficiente y a la falta de una información cronológica más precisa) parecen contrastar con la información recabada en cementerios rurales mayas, como muestran los estudios de Cozumel y Tankah en Quintana Roo y de Tipu en Belice (Saul, 1982; Havill et al., 1997), cuya conclusión apunta hacia la continuidad del modelado cefálico entre mayas rurales durante el siglo xvı. Interesa destacar también que la urna infantil de la época colonial hallada en el sitio de Sihó, Yucatán, muestra poderosamente la permanencia de las costumbre mortuorias autóctonas prehispánicas (Fernández et al., 2010). La bóveda craneana del infante ostenta un notable aplanamiento cultural del tipo tabular erecto que había sido logrado mediante el empleo de una cuna deformatoria durante sus primeros meses o años de vida.

Podemos especular que la pervivencia del ritual prehispánico (que se manifiesta tanto en la colocación del difunto infante en urna como en su modificación cefálica) se vio favorecida al ubicarse esa zona en una región apartada de la península yucateca, lejos de la influencia de las instituciones coloniales que irradiaban desde los pocos centros urbanos y conurbanos de la provincia. Sabemos que hasta finales del siglo xviII las zonas rurales estaban, por lo general, a cargo no directamente de representantes españoles sino de intermediarios mayas, quienes ejercían el mando en sus pueblos. Se habían conformado los pueblos de indios con sus propios consejos, a imagen y semejanza de las ciudades o villas españolas, a cuya cabeza se situaba el cacique aunque, a la vez, dominados espiritualmente por la doctrina correspondiente, en un proceso que arranca desde inicios de la Colonia (Bracamonte y Solís, 1996: 66-76). En la práctica, este sistema concedía un considerable grado de libertad a las autoridades nativas locales y una relativa autonomía política a la sociedad rural en sí (Farriss, 1984: 356-357). 
Habría que ampliar el marco de estos estudios para poder profundizar sobre las tendencias aquí asentadas, en particular la comparación entre poblaciones mayas rurales y urbanas.

En todo caso, podemos asumir que la relativa autonomía rural donde el control político y religioso era más endeble o incluso nulo en zonas alejadas o de selva, debe haberse traducido en la pervivencia de las costumbres de antaño. Esto podría explicar el patrón observado en cráneos examinados recientemente durante un recorrido por santuarios cavernosos de la región lacandona del norte de Mensabak, Chiapas (Tiesler et al., 2010). Las calotas forman parte de cúmulos de restos humanos que, a su vez, están vinculados con los espacios sagrados. En su mayoría deben haber sido depositados en tiempos coloniales o incluso contemporáneos, si creemos en los testimonios orales que recibimos de los indígenas lacandones y si consideramos las huellas de impacto con arma blanca metálica que algunos restos muestran. Para los fines de este trabajo interesa que las 21 calotas registradas muestran modificaciones artificiales. Lucían siempre una configuración tabular erecta, con o sin surco sagital, lograda con cunas compresoras (Tiesler et al., 2010; figura 2).

Sobre el uso de cunas infantiles entre los lacandones históricos (y con ello posiblemente su modificación cefálica artificial) versan varios testimonios. Los

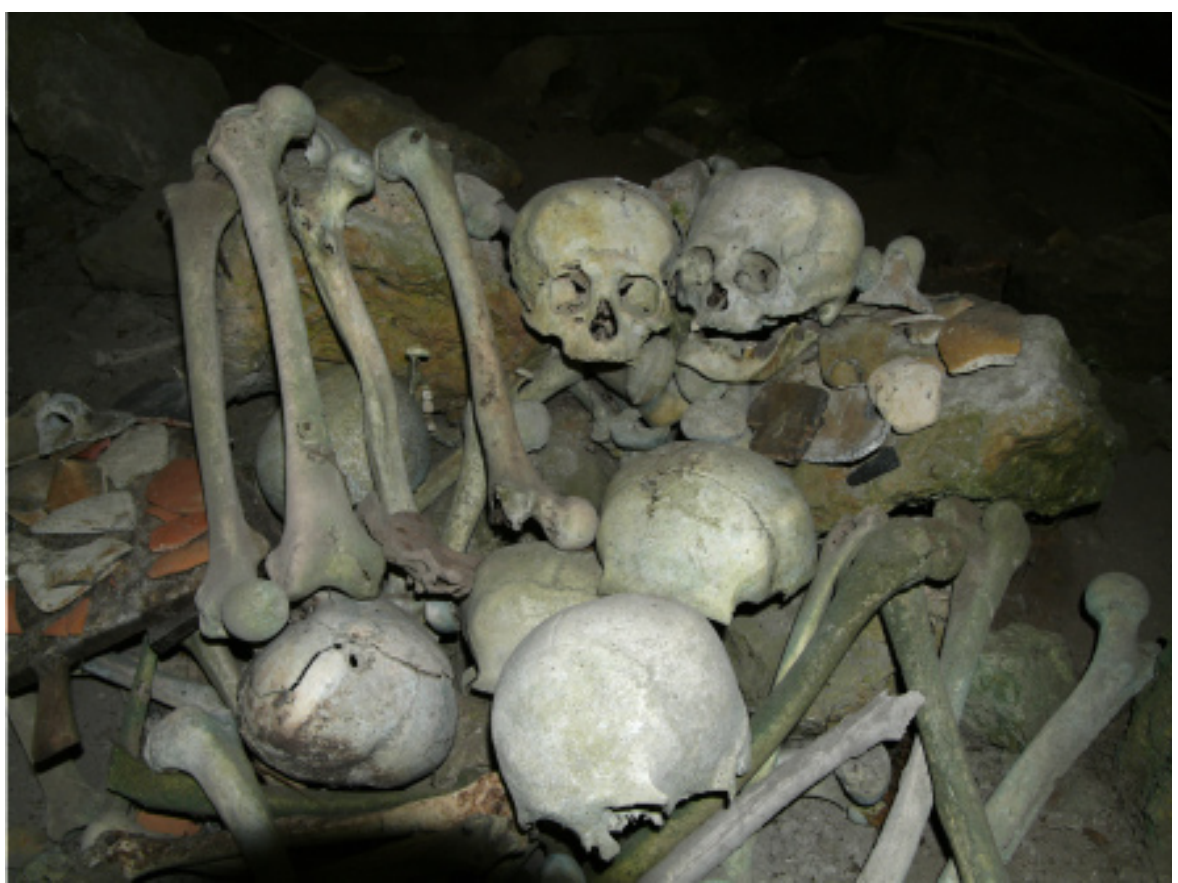

Figura 2. Arreglo de huesos humanos en un abrigo rocoso, usado como santuario por lacandones de Mensabak, Chiapas. Todos los cráneos muestran modificación cultural de la modalidad tabular erecta, con o sin señas de banda sagital 
últimos registros escritos de la práctica datan de principios del siglo xx. Entonces se menciona que las cunas portátiles lacandonas estaban confeccionadas de carrizo o de tela y colgaban del techo de los hogares en que los indígenas habitaban dentro de las zonas selváticas. Otro testigo fue David Amram, quien viajó por estos lares en los años treinta del siglo pasado y quien afirma que algunos lacandones lugareños todavía lucían su frente aplanada (Amram, 1937: 237; Palka, 2005: 224).

\section{A manera de conclusión}

El cambio violento en todos los aspectos que produjo la conquista europea sobre las sociedades dominadas tuvo también su contrapunto en aquellas costumbres que, como la modificación craneana, formaban parte importante del repertorio cultural autóctono. En el caso de la modificación de la cabeza, estaba destinada irremediablemente al abandono. En este trabajo hemos intentado vislumbrar los significados culturales que la modificación cefálica prehispánica pudo tener para las poblaciones autóctonas en un momento crítico —el contacto europeo- desde una mirada alterna: a través de la perspectiva adoptada por los cronistas. De este modo, buscamos propiciar una visión más engranada culturalmente sobre motivos, formas y técnicas empleadas en los modelados cefálicos. Hay que tener en cuenta que dichos cronistas fueron testigos presenciales en muchas ocasiones de esta tradición, vieron con sus propios ojos los cráneos modificados artificialmente y trataron de describir o explicar estas deformaciones como parte de las características físicas de las poblaciones conquistadas. Fueron estas visiones de los cronistas españoles lo que nos llevó a plantear nuevas reflexiones acerca de la supervivencia, abandono o sustitución del modelado y nos han proporcionado puntos de partida invaluables para examinar los significados culturales autóctonos de dicha práctica, que en este trabajo hemos ubicado en la esfera ideológica sobre el cuerpo y en la dimensión ritual que tenían los mayas. Todo da a entender que no era tan sólo un aditamento o una moda lo que inducía a las madres a colocar a su infante en una cuna protectora y compresora, sino al parecer era un acto cotidiano, el mismo que protegía y preparaba al menor para consagrar su posterior integración formal en el seno de la comunidad.

En segundo lugar, hemos examinado la información de poblaciones esqueléticas mayas de la época colonial, la cual parece remarcar el hecho constatable del descenso en los porcentajes de individuos que ostentan la práctica deformatoria, independientemente del número de las muestras observadas. Dentro de este patrón, nos pareció muy significativo constatar que la frecuencia de cráneos modelados desciende aún más si los restos provienen de cementerios ubicados en el ámbito urbano, espacios donde debió haber regido un mayor control religioso y político. Esto conllevaría una mayor celeridad en la pérdida de las costumbres autóctonas de los individuos que habitaban en estos lugares. 
Está claro que, independientemente de la interpretación que pudieran dar los nuevos poderes civiles o religiosos a esta práctica ancestral maya, sería primordial para ellos su erradicación. Los cráneos modificados constituían un atributo visible asociado a otra identidad, a su vez vinculada con el mundo prehispánico. Su pervivencia podía provocar una continuidad de prácticas y costumbres ancestrales, cuando lo que se pretendía era, precisamente, su erradicación y la uniformidad y subordinación a las nuevas creencias y formas de vida de los colonizadores; en definitiva, el objetivo era lograr la aculturación total del mundo indígena. Aún más, si tales prácticas se identificaban con algún sentido ritual que pudiera mantener alguna relación con el pensamiento religioso que los españoles pretendían erradicar totalmente.

Es cierto que las descripciones de algunos cronistas tienden más a tratar de entender el por qué de tales prácticas, mientras otros sólo las describen desde el punto de vista de la vestimenta o el ornato; pero tanto en unos como en otros se advierte un lenguaje condenatorio hacia las mismas. Aún en el caso de aquéllos que consideraban la modificación de los niños como una práctica terapéutica, en sus textos se lee implícita la denostación hacia tal costumbre. Y, aún más, si el planteamiento se hacía desde un punto de vista teológico o moral, esto es, si se descubría cualquier atisbo de connotación religiosa o de asociación con los dioses prehispánicos en la costumbre de la deformación craneana. La identificación de las deidades indígenas con el demonio católico tenía como consecuencia que toda forma ritual fuera considerada sacrílega. Por tanto, la modificación craneana fue cayendo en desuso bien por asimilación estratégica de los indígenas a la población dominante o por imposición o prohibición (más por esto último si tenemos en cuenta que, según señalan los restos analizados, fue rápida su desaparición: las costumbres ancestrales no se desvanecen tan rápido de forma natural).

A pesar de todo lo anterior, estas prácticas corporales no desaparecieron por completo. Al igual que otros rituales y costumbres, su pervivencia está atestiguada hasta fechas muy recientes, pero en lugares aislados, rurales o selváticos, dispersos o alejados de los centros de control, indicio de la lentitud con que se producen los cambios de mentalidad y lo arraigado de estas costumbres en algunos pueblos.

\section{BIBLIOGRAFÍA}

Amram, David W.

1937 "Eastern Chiapas”, The Geographical Review, 27: 19-36. Nueva York: American Geographic Society.

Barrera Vázquez, Alfredo (ed.)

1938 Fray Diego de Landa. Relación de las cosas de Yucatán. Mérida: Edición Yucateca. 
Beristáin, Francisco

1996 El templo dominico de Osumacinta, Chiapas. Excavaciones arqueológicas. México: Instituto Nacional de Antropología e Historia.

Blom, Deborah E.

2005 "Embodying Borders: Human Body Modification and Diversity in Tiwanaku Society", Journal of Anthropological Archaeology, 24: 1-24. Amsterdam: Elsevier.

Bonavides, Enrique

1992 "Ritos de pasaje entre los mayas antiguos", Estudios de Cultura Maya, XIX: 397-425. México: Universidad Nacional Autónoma de México, Centro de Estudios Mayas.

Bracamonte y Sosa, Pedro y Gabriela Solís Robleda

1996 Espacios mayas de autonomía. El pacto colonial en Yucatán. Mérida: Universidad Autónoma de Yucatán.

Casas, Bartolomé de las

1967 Apologética historia sumaria, Edmundo O'Gorman (ed.). México: Universidad Nacional Autónoma de México, Instituto de Investigaciones Históricas, 2 vols.

Castillo, Cristóbal del

$2001 \quad H i s t o r i a$ de la venida de los mexicanos y de otros pueblos e historia de la Conquista. México: Consejo Nacional para la Cultura y las Artes.

Chuchiak IV, John F.

2006 "Yaab Uih Yetal Maya Cimil: Colonial Plagues, Famines, Catastrophes and their Impact on Changing Yucatec Maya Concepts of Death \& Dying, 15701794", Jaws of the Underworld. Life, Death, and Rebirth Among the Ancient Maya. Pierre Colas, Geneviéve LeFort y Bodil Liljefors Tersson (eds.). Markt Schwaben: Anton Saurwein (Acta Mesoamericana, 16), 3-18.

Cieza de León, Pedro

1984 La Crónica del Perú, Manuel Ballesteros (ed.). Madrid: Historia 16.

Códice de la Real Academia de la Historia

1926 Edición facsímil y comentarios por Francisco del Paso y Troncoso. México: Museo Nacional de México.

Dávalos Hurtado, E.

1951 "La deformación craneana entre los tlatelolca", tesis de licenciatura y maestría en Antropología Física. México: Escuela Nacional de Antropología e Historia/Instituto Nacional de Antropología e Historia.

D'Olwer, Luis N. (comp.)

1963 Cronistas de las culturas precolombinas. México: Fondo de Cultura Económica. 
Farris, Nancy M.

1984 Maya Society under Colonial Rule. The Collective Enterprise of Survival. Princeton: Princeton University.

Fernández, Lilia, Rafael Cobos, Socorro Jiménez, Christopher Goetz y Vera Tiesler

2010 "Morir al filo del tiempo: una urna funeraria infantil colonial en Sihó, Yucatán”, Mexicon, 32 (4): 82-87. Markt Schwaben: Anton Saurwein.

Havill, Lorena M., Diane M. Warren, Keith P. Jacobi, Karen D. Gettelman, Della Collins Cook, y K. Anne Pyburn

1997 "Late Postclassic Tooth Filing at Chau Hiix and Tipu, Belize", Bones of the Maya: Studies of Ancient Skeletons. Stephen L. Whittington y David M. Reed (eds.). Washington, D. C.: Smithsonian Institution, 89-104.

Hernández, Francisco

2001 Antigüedades de la Nueva España. Madrid: Dastin [s. f.].

Landa, fray Diego de

1982 Relación de las cosas de Yucatán. México: Porrúa.

$[\sim 1566]$

López Austin, Alfredo

1989 Cuerpo humano e ideología (las concepciones de los antiguos nahuas). México: Universidad Nacional Autónoma de México.

2001 "El núcleo duro, la cosmovisión y la tradición mesoamericana”, Cosmovisión, ritual e identidad de los pueblos indígenas de México. Johanna Broda y Felix Baez-Jorge (coords.). México: Fondo de Cultura Económica, 47-65.

López de Gómara, Francisco

1987 La Conquista de México, José Luis de Rojas (ed.), Madrid: Historia 16.

[1552]

Molina Solís, Juan Francisco

1943 Historia del descubrimiento y conquista de Yucatán, tomo III. México: Ediciones Mensaje.

Neumann, Georg K.

1942 "Types of Artificial Cranial Deformation in the Eastern United States", American Antiquity, 3: 307-318. Washington, D. C.: Society for American Archaeology.

Palka, Joel W.

2005 Unconquered Lacandon Maya. Ethnohistory and Archaeology of Indifenous Culture Change. Gainesville: University Press of Florida.

Pardal, Ramón

1938 "La deformación intencional del cráneo por los indios de América", Actas Ciba Argentina, 3: 67-80. Buenos Aires: Actas Ciba. 
Real Academia Española

1990 Diccionario de Autoridades. Madrid: Gredos, 3 vols.

Romano Pacheco, Arturo

1965 Estudio morfológico de la deformación craneana en Tamuín, S.L.P., y en la Isla del Idolo, Veracruz. México: Instituto Nacional de Antropología e Historia (Serie de Investigaciones, 10).

1974 "Deformación cefálica intencional”, Antropología física, época prehispánica, Juan Comas (ed.). México: Instituto Nacional de Antropología e Historia, 197-227.

Sahagún, fray Bernadino de

1989 Historia general de las cosas de Nueva España. México: Porrúa.

Saul, Frank P.

1982 "The Human Skeletal Remains from Tancah, Meco", On the Edge of the Sea. Arthur G. Miller (ed.). Washington, D. C.: Dumbarton Oaks/Harvard University, 115-128.

Stephens, John y Frederick Catherwood

1963 Incidents of Travel in Yucatan. Nueva York: Dover, 2 vols.

[1843]

1969 Incidents of Travel in Central America, Chiapas, and Yucatan. Nueva York: Dover,

[1841] 2 vols.

Stewart, T. Dale

1974 Human Skeletal Remains from Dzibilchaltun, Yucatan, Mexico, with a Review of Cranial Deformity Types in the Maya Region. Nueva Orleans: Tulane University, Middle American Research Institute (Publication 31, number 7: 199-225).

Tiesler, Vera

1998 La costumbre de la deformación cefálica entre los antiguos mayas: aspectos morfológicos y culturales. México: Instituto Nacional de Antropología e Historia (Colección Científica).

1999 "Rasgos bioculturales entre los antiguos mayas: aspectos arqueológicos y sociales", tesis de doctorado en Antropología. México: Universidad Nacional Autónoma de México, Facultad de Filosofía y Letras.

2001 "La muerte del general Bernadino Cen, líder de la Guerra de Castas", Temas Antropológicos, 23 (1): 83-99. Mérida: Universidad Autónoma de Yucatán.

2006 "¿Hubo trepanación en la antigua sociedad maya? Una apreciación regional”, Antropología Física Latinoamericana, 4: 169-218. México: Universidad Nacional Autónoma de México, Instituto de Investigaciones Antropológicas.

s.f. "Transformándose en maya. El modelado cefálico entre los mayas prehispánicos y coloniales". Manuscrito.

Tiesler, Vera y Andrea Cucina

2010 "La deformación cefálica como emblema de identidad, etnicidad y reproducción cultural entre los mayas del Clásico", Identidades y cultura material 
en la región maya. Héctor Hernández y Marcos Pool (eds.). Mérida: Universidad Autónoma de Yucatán, 111-134.

Tiesler, Vera, Andrea Cucina, Shintaro Suzuki y Julio Chi

2010 "Proyecto Arqueológico Mensabak, Chiapas. Estancia 6/2010". Reporte inédito, Mérida: Universidad Autónoma de Yucatán.

Tiesler, Vera e Iván Oliva

2010 "Identity, Alienation, and Integration: Body Modifications in the Early Colonial Population from Campeche", Natives, Europeans, and Africans in Colonial Campeche. History and Archaeology. Vera Tiesler, Pilar Zabala y Andrea Cucina (eds.). Gainesville: University Press of Florida, 130-151.

Tiesler, Vera, Pilar Zabala y Agustín Peña

2003 "Vida y muerte en Mérida durante los siglos xvı y xvı", Mérida Miradas Múltiples. Francisco Fernández Repetto y José Fuentes Gómez (eds.). México: Cámara de Diputados, 41-55.

Torres-Rouff, Christina

2002 "Cranial Vault Modification and Ethnicity in Middle Horizon San Pedro de Atacama, North Chile”, Current Anthropology, 43 (1): 163-171. Chicago: University of Chicago.

2003 "A Bioarchaeological Analysis of Crania from Pachacamac, Peru”, American Journal of Physical Anthropology, Supplement, 36: 210. Nueva York: Wiley.

Weiss, Pedro

1962 Tipología de las deformaciones cefálicas de los antiguos peruanos, según la osteología cultural. Lima: Sobretiro de la Revista del Museo Nacional, t. XXXI, $15-42$.

1967 "Ensayo de osteología cultural en Guatemala”, Antropología e Historia de Guatemala XIX: 14-26. Guatemala: Instituto de Antropología e Historia.

Zabala, Pilar

2009 "Fuentes para el estudio de los sacrificios humanos en la época colonial", Temas Antropológicos, 31: 5-23. Mérida: Universidad Autónoma de Yucatán. 